\title{
KOMUNITAS RERESIK SAMPAH VISUAL: MEMBANGUN KESADARAN BARU TATA VISUAL IKLAN MEDIA LUAR GRIYA DI YOGYAKARTA
}

\author{
Hesti Rahayu \\ Dosen Program Studi Disain Komunikasi Visual \\ Jurusan Disain, FSR ISI Yogyakarta \\ nadacintaku@gmail.com
}

\begin{abstract}
The subject of this research is the Reresik Sampah Visual (RSV) community, its efforts and activities in building new awareness of Yogyakarta people about the importance of a visual management should be applied to the out of home (OOH) advertising in Yogyakarta. New awareness will result in a new culture; a culture that is more environmentally friendly. It is hoped that this culture will finally restore the aesthetic and visual management of the $\mathrm{OOH}$ advertising that is more comfortable for the public.

A qualitative method of research is employed to descriptively analyze the data gathered from observations, interviews, documentations and library study.

To gain its objective, the RSV community incessantly campaigns its opinions based on the Five Percepts of $R S V$. The opinions are buzzed by raiding the $\mathrm{OOH}$ ads placed on streets, forming community via social media networking, writing on the mass media, and undertaking discussion forums. The RSV activity is a local movement that is similar to the New Social Movement fighting for the improvement of the quality of life and focuses on the non economy redistribution and non violence issues.
\end{abstract}

Keywords: Community, Reresik Sampah Visual, Visual management, New awareness, Out of home Advertising.

Relevance to Visual Communication Design Practice: This article reports how the Komunitas Reresik Sampah Visual practically seeks a more comfortable visual management in public spaces. It is an application of visual communication design knowledge.

\section{PENDAHULUAN}

Perbincangan mengenai semrawutnya iklan media luar griya (Out of Home Media = $O O H)$ di jalanan Yogyakarta sebenarnya bukan hal yang baru, meskipun demikian tetap saja hal ini menarik untuk dibahas. Begitu banyaknya billboard, poster, spanduk, shop sign yang terdapat di jalanjalan merupakan satu gejala dari gaya hidup zaman ini yang menandakan konsumsi dan produksi image yang makin meningkat.

Peningkatan ini sebenarnya telah diupayakan antisipasinya oleh pemerintah daerah dengan menetapkan berbagai regulasi yang mengatur keberadaan mediamedia visual luar griya. Ironisnya, tetap saja terjadi pelanggaran aturan yang mengakibatkan apa yang diistilahkan dengan "sampah visual". Iklan-iklan media 
luar griya yang berbayar maupun tidak, seakan saling berkontestasi untuk berlombalomba dilihat - yang sayangnya seringkali justru menimbulkan rasa ruwet dan pusing.

Iklan media luar griya yang menempati ruang publik, meskipun ruang publik keberadaannya bebas sebagai sarana opini masyarakat, akhirnya tak pelak menjadi arena 'perebutan' kekuasan. Ruang publik kemudian berubah menjadi 'ruang privat' bagi sebagian kelompok dan seolah 'menindas' kelompok yang lain. Akibatnya, kepentingan 'publik' sebagai pemilik yang sesungguhnya atas ruang publik menjadi terabaikan.

Upaya-upaya untuk mengembalikan ruang publik menjadi milik publik kembali, kemudian memunculkan berbagai aksi dan komunitas di wilayah Yogyakarta. Misalnya saja komunitas Bike to Work, Komunitas Jogja Last Friday Night dan Paguyuban Onthel Jogja yang berupaya mengembalikan ruang bersepeda bagi warga kota Yogyakarta, Komunitas Peta Hijau yang berupaya mengembalikan ruang terbuka hijau dalam ruang publik, komunitaskomunitas street art yang berupaya mengisi pesan-pesan peduli lingkungan dalam karyakaryanya, serta Komunitas Reresik Sampah Visual yang secara rutin berupaya membersihkan/ mencabuti iklan-iklan media luar griya yang tidak sesuai penempatannya dan dianggap merusak lingkungan.

Komunitas Reresik Sampah Visual digagas dan dimotori oleh Sumbo Tinarbuko. Dosen Desain Komunikasi Visual Institut Seni Yogyakarta ini bersama para relawan yang bergabung bersamanya, mencabuti iklan-iklan yang penempatannya tidak sesuai. Sebagai pedoman gerakannya, dia menetapkan rambu-rambu yang disebutnya Lima Sila Sampah Visual. Sumbo mulai membahas tentang sampah visual sejak dia diminta untuk mengajar mata kuliah kritik desain dan iklan. Sumbo juga menjadi anggota Badan Pengawasan Periklanan dari Persatuan Perusahaan Periklanan Indonesia pengda (pengurus daerah) DIY.

Komunitas Reresik Sampah Visual awal digagas sejak empat tahun lalu, yaitu di tahun 2009 dan akhirnya Sumbo terjun langsung menumpas teror sampah visual tersebut. Aksi pertamanya pada 19 Mei 2012, dia menggandeng mahasiswa ISI untuk mencabuti reklame liar di sepanjang Jalan Sewon, Bantul, Yogyakarta. Ternyata, respon masyarakat cukup positif, namun belum ada tanggapan dari pemerintah terkait aksi itu. Baru pada aksi-aksi selanjutnya, Sumbo berhasil menggandeng 
pejabat pemerintah antara lain walikota Yogyakarta dan bupati Bantul.

Sumbo aktif mengkritik perihal sampah visual tersebut dengan tulisannya di surat kabar dan di kegiatan belajar-mengajar. Selain itu, Sumbo juga aktif berkampanye di jejaring sosial Twitter (@sumbotinarbuko, @sampah_visual) dan $\quad$ Facebook (facebook.com/sumbotinarbuko, facebook.com/SampahVisual). ${ }^{1}$

Penelitian ini memfokuskan pembahasannya terhadap Komunitas Reresik Sampah Visual dan upaya serta aktivitasnya dalam membangun kesadaran baru mengenai pentingnya penataan visual media luar griya di Yogyakarta. Kesadaran baru akan membentuk budaya baru, budaya yang lebih peduli terhadap lingkungan dan pada akhirnya diharapkan dapat mengembalikan estetika dan tata visual iklan media luar griya yang lebih nyaman bagi publik. Untuk itu tulisan ini menguraikan permasalahan yang meliputi: apa dan bagaimanakah komunitas Reresik Sampah Visual peran dan aktivitasnya, serta bagaimana Reresik Sampah Visual sebagai aksi dan komunitas dalam proses

$1 \mathrm{http}$ //intisari-online.com/read/sampah-visual-3sumbo-tinarbuko-bebersih-sampah-visual accesed on December, 10, 2013. membangun kesadaran baru tata visual iklan media luar griya di Yogyakarta.

Metode penelitian yang digunakan adalah metode kualitatif, bersifat deskriptif analisis. Dalam penelitian ini, gaya hidup, cara pandang, ataupun ungkapan emosi pada komunitas yang diteliti diperlakukan sebagai data (Moleong, 1999). Data dibedakan menjadi dua, yaitu data primer dan sekunder. Data primer diperoleh melalui penelitian lapangan yaitu dengan observasi dan wawancara, sedangkan data sekunder didapatkan dari dokumentasi dan berbagai sumber pustaka.

\section{IKLAN DAN SAMPAH VISUAL}

Periklanan di Indonesia memiliki sejarah panjang sejak zaman Hindia Belanda. Diawali oleh Gubernur Jendral Hindia Belanda saat itu, Jan Pieterzoon Coen dengan silografi (tulisan indah) yang dibuatnya. Pada saat itu Belanda menerbitkan sebuah pamflet informasi semacam surat kabar dengan tulisan tangan, Memorie De Nouvelles. Dengan media berkala inilah Coen mengirimkan berita dari Pemerintah Hindia Belanda, khususnya yang menyangkut mutasi dan promosi para pejabat penting di kawasan itu. Tulisan tangan Coen yang indah itu ternyata merupakan refleksi dari naluri bersaing pemerintah Hindia Belanda dengan 
Portugis. Kedua negara tersebut terlibat persaingan perebutan hasil rempah-rempah di kepulauan Maluku, dan Coen "menulis" iklan untuk melawan aktivitas perdagangan Portugis (Winarno : 2008).

Periklanan kemudian berkembang dan melampaui berbagai fase mulai dari masa penjajahan Belanda, masa depresi ekonomi Eropa yang berimbas ke negara-negara jajahan, masa penjajahan Jepang, masa awal kemerdekaan, hingga masa periklanan Indonesia modern (Setiono (ed.): 2004). Dalam perkembangannya iklan tidak dapat dipisahkan dari media massa terutama koran. Bahkan dapat dikatakan bahwa iklanlah yang menghembuskan napas awal bagi kehidupan surat kabar di Indonesia dan bukan sebaliknya (Winarno: 2008). Ini mengindikasikan bahwa iklan merupakan sarana penting dalam meraup uang dalam rangka perputaran modal dan produksi.

Di masa sekarang, periklanan disajikan dalam berbagai strategi dan visual yang mewarnai media massa, ruang-ruang privat dan ruang-ruang public baik di desa maupun kota. Ditambah dengan dinamika kemajuan zaman dan perkembangan teknologi, periklanan menjadi semakin canggih dan akhirnya mengakibatkan apa yang disebut oleh Jean P. Baudrillard sebagai “overload communication".
Overload communication di ruang public inilah yang mengakibatkan terjadinya "sampah visual". Istilah sampah visual yang dimaksud dalam tulisan ini mengacu pada pendapat Sumbo Tinarbuko yang menyatakan bahwa "sampah visual" adalah iklan-iklan yang menggunakan media luar griya/ media luar ruang yang dalam upaya pemanfaatan, pemilihan, dan pemasangannya di berbagai tempat strategis di sudut kota berjubel, saling timpa, dan menimbulkan keruwetan.

Media luar griya merupakan salah satu media di antara berbagai alternatif media beriklan. Dalam teori periklanan, berdasarkan media yang digunakan, iklan terbagi menjadi dua jenis yaitu iklan cetak dan iklan elektronik (Widyatama, 2007). Iklan cetak yaitu iklan yang dibuat dan dipasang dengan menggunakan teknik cetak, baik cetak dengan teknologi sederhana maupun teknologi tinggi. Beberapa bentuk iklan cetak yaitu : iklan cetak surat kabar, iklan cetak majalah, tabloid, iklan cetak baliho, iklan cetak poster, iklan leaflet, iklan spanduk, flyers, kemasan produk, stiker, balon udara, bus panel, dan berbagai iklan cetak lainnya. Adapun iklan elektronik, disebut iklan elektronik karena media yang digunakan sebagai tempat dipasangnya pesan iklan 
adalah karena menggunakan media yang berbasis perangkat elektronik. Secara spesifik iklan elektronik dapat dibagi dalam 4 jenis, yaitu iklan radio, iklan televisi, iklan film, serta iklan yang dipasang dalam media jaringan/ internet. Iklan media luar griya adalah iklan yang penempatannya berada di ruang terbuka publik. Wujud yang lazim ditemui di Indonesia adalah baliho, poster, spanduk, stiker, balon udara, bus panel, videotron, dan sebagainya.

Di kota Yogyakarta sendiri, ada sekitar 465 titik pemasangan reklame resmi yang ditetapkan pemerintah kota Yogyakarta ${ }^{2}$. Titik-titik reklame resmi inilah yang menyumbang pajak reklame ke pemkot Yogyakarta. Menurut Liputan Koran Tempo, Senin, 16 September $2013^{3}$, rata-rata pajak yang diterima per tahun dari reklame hanya Rp 5 miliar. Tidak sebanding dengan total pendapatan asli daerah yang sekitar Rp 180 miliar. Inilah yang kemudian kadang menimbulkan permasalahan karena selain nilai pajaknya yang dinilai rendah, kenyataan di lapangan menunjukkan bahwa ada banyak sekali pemasang iklan luar griya yang tidak membayar pajak dan menempati

\footnotetext{
${ }^{2}$ http://hukum.jogjakota.go.id/data/09-075.pdf. accesed on December, 16, 2013.

${ }^{3} \mathrm{http}: / /$ sampahvisual.com/sumbo-tinarbuko-kuotaizin-reklame-harus-diatur/ accesed on December, 10, 2013
}

lokasi-lokasi yang berada di luar titik yang ditentukan pemerintah. Atau sebaliknya, banyak juga pengiklan yang memasang alat peraga reklamenya di titik-titik di luar ketentuan pemerintah, tetapi merasa tidak ada masalah karena telah membayar pajak. Ini menjadi dilema tersendiri dan turut memperkeruh permasalahan mengenai sampah visual.

\section{RERESIK SAMPAH VISUAL SEBAGAI AKSI DAN KOMUNITAS}

Menurut penuturan penggagas Reresik Sampah Visual (RSV) yaitu Sumbo Tinarbuko, yang pertama dia lontarkan kepada publik adalah istilah "sampah visual". Istilah ini awalnya merupakan salah satu hal yang dibahas dalam kuliah Kritik Desain Komunikasi Visual di Jurusan Desain, Fakultas Seni Rupa ISI Yogyakarta. Saat itu Sumbo mengajak mahasiswanya untuk berpikir kritis dan menganalisis fenomena "sampah visual" yang bertebaran di ruang-ruang publik di Yogyakarta. ${ }^{4}$

Pembahasan mengenai "sampah visual" ini kemudian menginspirasi dan menggerakkannya untuk melakukan

\footnotetext{
${ }^{4}$ Berdasarkan penuturan Sumbo Tinarbuko dalam diskusi SesiSenja\#7 :: bADVisual Syndrome :: Bersama, Drs. Sumbo Tinarbuko, M.Sn (ISI), Edwi Arif Sosiawan, SIP, M.Si (UPN), Affi Aditya Khresna (BMC) feat : Brian "Jikustik" - Jumat, 4 Okt 2013, Jam 18.00 WIB di MIP Mara Advertising Jl. Mawar No. 22 Yogyakarta.
} 
langkah nyata yaitu dengan mendirikan komunitas "Reresik Sampah Visual”. Dalam aksinya, Komunitas RSV memiliki prinsip dasar mengenai iklan luar griya bagaimanakah yang musti di"reresik" (dibersihkan)? Prinsip dasar ini oleh Sumbo dinamai sebagai "5 Sila Reresik Sampah Visual” yang dari penyebutannya mengingatkan kita pada "5 sila Pancasila”. Isi dari 5 Sila Reresik Sampah Visual adalah sebagai berikut:

1. Iklan luar ruang tidak boleh dipasang di trotoar

2. Iklan luar ruang tidak boleh dipasang di taman kota atau Ruang Terbuka Hijau $(\mathrm{RTH})$

3. Iklan luar ruang tidak boleh dipasang di berbagai macam tiang (listrik, telpon, dll)

4. Iklan luar ruang tidak boleh dipasang di tembok atau bangunan heritage

5. Iklan luar ruang tidak boleh dipasang/diikat/dipaku di batang pohon

Di samping "5 Sila Reresik Sampah Visual" Sumbo juga menuturkan bahwa yang termasuk sampah visual adalah :

1. Iklan-iklan media luar griya yang dengan kuasa uang, seolah menjajah ruang public, membeli ruang public untuk ditukar dengan brand-brand dan merk-merk komersial. Akibatnya seolah ruang publik menjadi ruang privat bagi sekelompok pemilik modal yang mampu membayar sewa dan membayar pajak titik-titik reklame.

2. Iklan-iklan media luar griya yang tidak membayar pajak dan kemudian memenuhi ruang publik dengan beragam variasi iklan, mulai dari banner, rontek, spanduk, umbul-umbul dan sejenisnya.

Adapun keanggotaan RSV sifatnya tidak mengikat, tidak ada keanggotaan khusus, tidak ada struktur organisasi khusus seperti adanya ketua, sekretaris, dan bendahara. Dalam aksi sosialnya membersihkan sampah visual beberapa kali di kota Yogyakarta dan sekitarnya, Komunitas RSV dibantu oleh para sukarelawan dari kalangan mahasiswa, masyarakat biasa, dan juga dari anggota komunitas-komunitas lainnya yang ada di Yogyakarta.

Karena sifat keanggotaannya yang tidak mengikat inilah, maka Sumbo menyatakan bahwa esensi dasar dari Reresik Sampah Visual adalah pada kesadaran dan upaya yang dimiliki masing-masing orang untuk berani melakukan pembersihan sampah visual di sekitar rumahnya, dilakukan oleh dirinya dan anggota keluarganya, serta 
mengajak masyarakat sekitarnya. Jadi artinya Reresik Sampah Visual itu tidak harus menunggu berkumpulnya banyak orang yang kemudian menjadi suatu komunitas yang melakukan aksi bersama, tetapi justru yang terpenting dari RSV adalah pada "mental" untuk bersedia melakukan aksi Reresik Sampah Visual meskipun dilakukan per individu.

Pembentukan komunitas RSV dilakukan Sumbo dengan memanfaatkan jejaring social media, terutama melalui facebook dan twitter. Tak lupa, Sumbo juga membuat laman www.sampahvisual.com di samping laman pribadinya www.sumbotinarbuko.com yang berisikan isu-isu yang sengaja digulirkan terutama mengenai kampanye anti sampah visual.

Dalam tuntutannya untuk mewujudkan Kota Yogyakarta yang bersih dari sampah visual, setidaknya ada 7 Sikap Komunitas RSV yang terutama ditujukan kepada pemerintah daerah di Daerah Istimewa Yogyakarta, yaitu:

1. Komunitas RSV bukanlah tukang njabut (pencabut) sampah

2. Komunitas RSV tempat berkumpulnya anak muda yang peduli dengan ruang public serta peduli lingkungan hidup yang ramah secara ekologi visual.
3. Aktivitas Komunitas RSV mengajak siapa pun: pemerintah, anggota DPR, pejabat public, dan masyarakat luas dari berbagai profesi dan strata social untuk membangun kesadran bersama demi mewujudkan ruang public tetap menjadi milik publik, bukan diprivatisasi menjadi milik merek dagang, milik caleg, atau milik partai politik.

4. Provinsi Daerah Istimewa Yogyakarta, dengan window displaynya kota Yogyakarta harus menunjukkan keistimewaannya lewat penataan iklan luar ruang.

5. Ramah tidaknya sebuah kota bagi warga masyarakat dan wisatawan, salah satu indikatornya, sejauhmana pemerintah kota mampu menekan tebaran sampah visual yang cenderung menjadi teroris visual di ruang publik kota tersebut.

6. Mendesak walikota, bupati, dan DPRD kabupaten dan Kota Yogyakarta untuk membuat aturan hokum terkait dengan penataan iklan luar ruang.

7. Lima Sila Sampah Visual yang dibuat Komunitas Reresik Sampah Visual dapat dijadikan rujukan dalam membuat aturan hokum terkait dengan penataan iklan luar ruang. 


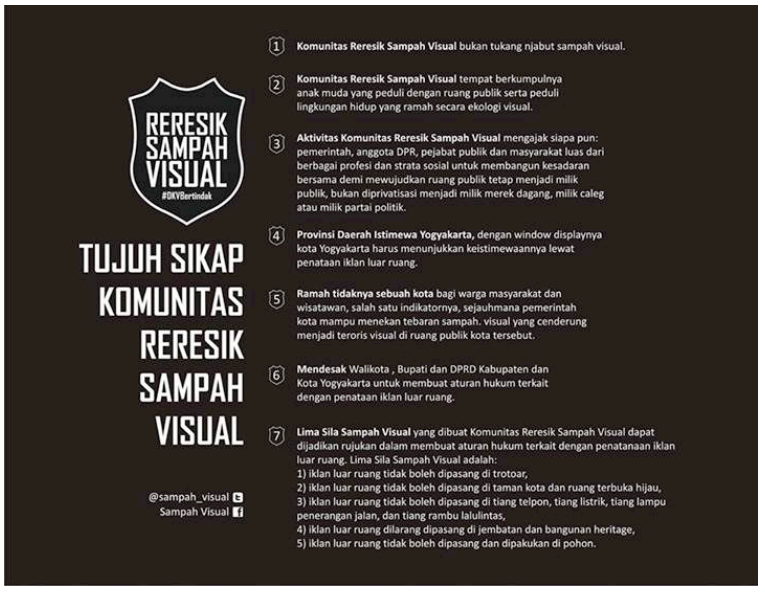

Gambar 1 Postingan di laman komunitas mengenai "7 Sikap Komunitas Reresik Sampah Visual" Sumber:

https://www.facebook.com/SampahVisual

Dalam setiap aksi Komunitas RSV ketika turun ke jalanan dan merazia iklaniklan luar griya yang tidak sesuai dengan 5 Sila RSV, didapati berkilo-kilo limbah sampah visual yang berupa spanduk, umbulumbul, rontek, banner, dan sebagainya. Kuantitasnya bisa satu atau dua mobil pickup, ditambah berkilo-kilo paku bekas yang tadinya digunakan untuk memakukan iklan di pohon-pohon. Sampah-sampah ini kemudian digunakan kembali/didaur ulang. Sebab jika kemudian hanya dibuang begitu saja, terasa sayang karena masih dapat dimanfaatkan kembali. Untuk itulah, maka RSV bekerjasama dengan seorang koordinator pengolah limbah sampah visual yaitu Hadi Paryanto.

Hadi Paryanto adalah seorang direktur bank. Bukan bank biasa, tetapi bank yang unik, yaitu Bank Sampah "Uwuh Minulyo". Bersama dengan timnya, limbah sampah visual disulap menjadi tas, tikar, rak sepatu, kap lampu, dan sebagainya. Bank Sampah “Uwuh Minulyo” berada di RW 7 Kelurahan Danurejan, Yogyakarta. Dengan demikian ada banyak aspek positif tambahan dari Komunitas RSV ini, yaitu aspek pemberdayaan ekonomi.

\section{PROSES MEMBANGUN KESADARAN BARU TATA VISUAL IKLAN MEDIA LUAR GRIYA}

Dalam wacana transformasi budaya, dikenal adanya pendapat Durkheim tentang representation individualle (gagasan individu) dan representations collective (gagasan kolektif), bahwa pada dasarnya semua individu saling berinteraksi meskipun mempunyai gagasan sendiri. Kemudian, interaksi gagasan individu ini membentuk gagasan kolektif yang dapat diterima dan dipahami bersama untuk membangun kebudayaan yang lebih besar. Sifat transformasi kebudayaan kualitatif atau ide dalam hal ini membutuhkan proses yang lebih lama untuk berubah (Sachari, 2001: 83).

Reresik Sampah Visual sebagai suatu aksi mengharapkan terjadinya opini umum berupa kesadaran mengenai pentingnya menjaga lingkungan dari sampah visual. Itu 
artinya RSV dalam prosesnya, tengah berupaya melakukan transformasi budaya di tengah masyarakat, bagaimana agar terjadi perubahan budaya yang semula tidak peka terhadap sampah visual menjadi kepekaan dan kesadaran bersama untuk menciptakan lingkungan dan ruang publik yang tata visualnya rapi dan bersih dari sampah visual. Penderasan opini ini dilakukan dengan beberapa cara:

1. Mengopinikan melalui tulisan-tulisan yang berupa gagasan-gagasan Sumbo di berbagai media massa, khususnya melalui rubrik Analisis Harian Kedaulatan Rakyat Yogyakarta. Dalam opini-opininya, Sumbo selalu menekankan dalam beberapa poin yaitu Pertama, desakan kepada pemerintah daerah untuk segera menyusun masterplan iklan luar ruang yang mampu mengontrol pemasangan reklame di ruang publik agar tidak menjadi terror visual. Kedua, kepada biro iklan, dan tukang pasang iklan bersama masyarakat umum, untuk memiliki keasadaran kolektif mengenai pentingnya menjaga ruang publik dari sampah visual. Ketiga, desakan kepada anggota dewan agar memutuskan raperda reklame yang lebih berorientasi pada harmonisasi antara pemerintah dan bukan hanya berorientasi pada peningkatan PAD (Pendapatan Asli Daerah). Keempat, desakan kepada para penegak hokum untuk lebih memaksimalkan sanksi hokum terhadap pelanggaran pemasangan iklan luar ruang di ruang public. ${ }^{5}$

2. Membentuk komunitas yang dimulai dari dunia maya (facebook, twitter, situs internet) dan aktif membuat status serta catatan-catatan yang diposting di akun komunitas. Harapannya, semua status dan catatan-catatan ini isinya dapat tersebarkan ke masyarakat luas. Dan berdasarkan pengamatan penulis, beberapa tulisan Sumbo dan konten berita komunitas tersebut telah dicopi dan di paste oleh beberapa pemilik blog yang mendukung semangat Reresik Sampah Visual. Selain itu, istilah "sampah visual" yang pada awal kemunculannnya terdengar asing, saat ini telah menjadi cukup lazim dikutip bahkan disebut oleh para jurnalis dan pejabat publik di Indonesia.

3. Menggalang aksi langsung di jalanan, baik bekerjasama dengan komunitas

http://sumbotinarbuko.com/sampah-visual-diruang-publik.html accesed on December, 10, 2013. 
lainnya, mengajak mahasiswa, atau bahkan dilakukan oleh Sumbo sekeluarga (isteri dan anak-anaknya). Dalam aksi melakukan reresik ini Sumbo selalu rajin mendokumentasikannya/memfotonya dan mengupload ke akun fb dan twitter pribadi dan komunitas. Untuk aksi-aksi yang lebih besar dan melibatkan komunitas-komunitas lainnya, Sumbo selalu mengundang wartawan untuk meliput. Aksi langsung Reresik Sampah Visual yang dilakukan dapat membantu tugas pemerintah, dalam hal ini satpol PP (satuan polisi pamong praja) untuk merazia iklan-iklan luar ruang yang tidak sesuai aturan. Selain itu dengan disiarkan dan diwartakan oleh komunitas ataupun oleh wartawan, maka akan mendapatkan efek penyebaran opini yang lebih meluas.

Dari beragam upayanya yang konsisten selama beberapa tahun ini, Sumbo sering menerima tawaran sebagai pembicara di berbagai forum terutama yang berkaitan dengan masalah iklan di ruang publik. Bahkan salah satu televisi swasta Indonesia yaitu Metro TV mengabadikan kegiatan Komunitas Reresik Sampah Visual ini dalam liputan Eagle Award Documentary Series yang ditayangkan bulan Oktober 2013 lalu. Akan tetapi bukan ketenaran maupun kesohoran yang dijadikan tujuan utama Sumbo dengan Komunitas RSV-nya. Harapan agar Kota Yogya menjadi kota yang ramah lingkungan, merupakan harapan utama dari upaya penyebaran opini ini.

Berikutnya adalah mengenai tata visual iklan media luar griya. Dengan berubahnya landscape komunikasi yang disebabkan oleh perkembangan teknologi maka pengelolaan media iklan tidak sekedar membutuhkan media planning tetapi juga communication design dan screen exposure management.

Yang dimaksud dengan perubahan landscape komunikasi adalah perubahan lanskap dalam dunia marketing komunikasi terutama karena adanya migrasi digital yang mengakibatkan terjadinya pergeseran cara berpromosi yang memaksa untuk menciptakan sinergi antara iklan tradisional, media massa, pemasaran langsung (direct mail), online dan pemasaran web, media sosial dan mobile marketing. Satu hal yang pasti, ada kecenderungan meningkat menuju "lebih digital". 


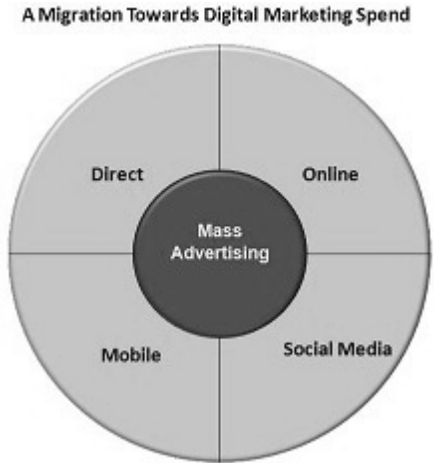

Sumber : http://www.gcworldbiz.com/blogscolumns/partner_relationships/bid/102103/TheChanging-Landscape-of-MarketingCommunications

Sedangkan communication design is a mixed discipline between design and information-development which is concerned with how media intermission such as printed, crafted, electronic media or presentations communicate with people. A communication design approach is not only concerned with developing the message aside from the aesthetics in media, but also with creating new media channels to ensure the message reaches the target audience. Some designers use graphic design and communication design interchangeably due to overlapping skills.

Communication design can also refer to a systems-based approach, in which the totality of media and messages within a culture or organization are designed as a single integrated process rather than a series of discrete efforts.
Communication design seeks to attract, inspire, create desires and motivate the people to respond to messages, with a view to making a favorable impact to the bottom line of the commissioning body, which can be either to build a brand, move sales, or for humanitarian purposes. Its process involves strategic business thinking, using market research, creativity, and problem-solving. Communications designers translate ideas and information through a variety of media. Their particular talent lies not only in the traditional skills of the hand, but also in their ability to think strategically in design and marketing terms.

The term communication design is often used interchangeably with visual communication, but has an alternative broader meaning that includes auditory, vocal, touch and smell. Examples of communication design include information architecture, editing, typography, illustration, web design, animation, advertising, ambient media, visual identity design, performing arts, copywriting and professional writing skills applied in the creative industries ${ }^{6}$.

Adapun Screen exposure management maksudnya adalah mengenai intensitas

\footnotetext{
${ }^{6}$ http://en.wikipedia.org/wiki/Communication_desig $\mathrm{n}$ accesed on December, 18, 2013.
} 
paparan layar yang tersaji ke hadapan audiens yang musti diatur agar dapat sesuai dengan target komunikasinya.

Dari sini maka tata visual iklan media luar griya sesungguhnya tengah berhadapan dengan landscape komunikasi yang berkembang tersebut. Dengan demikian maka tata visual iklan media luar griya saat ini yang dibutuhkan bukan hanya bicara point billboard, tapi juga public eye management. ${ }^{7}$ Point billboard adalah titiktitik yang disediakan pemerintah daerah di lokasi-lokasi tertentu di wilayah tersebut untuk dipasangi billboard, spanduk, dan iklan media luar griya lainnya secara berbayar (membayar pajak reklame dan sewa titik). Point billboard berpotensi menghasilkan keruwetan dan sampah visual ketika semua berlomba memasang iklan di point tersebut. Dengan demikian sifat pariwara/iklan semestinya berubah menjadi percakapan (conversation) yang ditunjang sosial media, bukan sekedar berjajar seolah berlomba-lomba untuk dilihat oleh audience yang melewatinya di jalanan.

\footnotetext{
7 Janoe Arijanto, dalam presentasinya di seminar Pinasthika Creative Festival 2012, 18 Oktober 2012, Hotel Melia Purosani Yogyakarta.
}

\section{KOMUNITAS RERESIK SAMPAH VISUAL SEBAGAI GERAKAN KEMASYARAKATAN/ GERAKAN SOSIAL (SOCIAL MOVEMENT)}

Tantangan yang dihadapi oleh Komunitas Reresik Sampah Visual bila tidak didukung oleh masyarakat luas, sebenarnya cukup kompleks. Ini terjadi karena setidaknya dua point: Pertama, di DIY terutama yang berada di Kota Yogyakarta, belum ada kesepahaman yang utuh antara asosiasi pengusaha, dengan para pemasang iklan luar griya yang tidak masuk keanggotaan asosiasi. Di Yogyakarta ada beberapa asosiasi atau organisasi perusahaan yang berkecimpung di dunia periklanan. Sebut misalnya PPPI (Persatuan Perusahaan Periklanan Indonesia) Pengda (Pengurus Daerah) DIY yang memayungi perusahaanperusahaan periklanan secara umum. Selain itu ada pula IBIY (Ikatan Billboard Indonesia Yogyakarta) yang beranggotakan perusahaan-perusahaan yang khusus menangani iklan media luar griya. Baik PPPI maupun IBIY, keduanya cukup komunikatif dan cukup sinergis dalam menjalin hubungan baik dengan Komunitas Reresik Sampah Visual. Hanya saja permasalahannya adalah terkadang para penebar sampah visual ini bukanlah bagian dari kedua organisasi ini. Inilah yang masih menimbulkan masalah. Di satu sisi ketika 
klaim sampah visual dialamatkan kepada organisasi, maka organisasi mengelak karena merasa sudah sesuai dengan aturan hokum dan menyesuaikan dengan peraturan pemerintah dalam pemasangan iklannya. Sedangkan bila klaim dialamatkan kepada pemasang iklan pencipta sampah visual non-anggota organisasi, maka klaim tidak dapat dilakukan karena mereka ada di luar lingkaran yang terkontrol oleh hukum. Oleh karenanya, maka jalan yang paling memungkinkan adalah dengan razia dan mengetatkan perda yang isinya melarang yang disertai sanksi kepada pemasang iklan di luar titik yang disediakan pemerintah. Di samping itu masterplan yang jelas mengenai reklame dan tatakota harus segera diwujudkan.

Kedua, sifat keanggotaan Komunitas RSV yang terbuka, longgar dan tidak mengikat. Sifat keanggotaan yang longgar dan tidak adanya susunan kepengurusan yang ketat memang menjadi dilemma tersendiri. Akan tetapi bila keanggotaan diperketat, maka dikhawatirkan memunculkan eksklusivitas. Sehingga jalan tengahnya adalah memaksimalkan kampanye Reresik Sampah Visual ini tidak pada penekanan keanggotaan, tetapi kampanye yang mendorong kesadaran individu maupun komunal untuk memiliki kesadaran kolektif yang sama.

Pengamatan terhadap Komunitas Reresik Sampah Visual, mengingatkan pada tipologi gerakan sosial baru (new social movement) periode ketiga yang muncul di Eropa, yaitu periode setelah era tahun 70 -an. Periode pertama gerakan sosial yang ada di Eropa dimulai pada dekade 40-an hingga 60an dan periode kedua di tahun 60 -an hingga 70-an. Gerakan sosial baru periode ketiga seringkali diamggap sebagai suatu gerakan yang terpisah dari Gerakan Sosial sebelumnya yang diwarnai politik kelas tradisional gerakan buruh. Perbedaan yang mendasar adalah dalam hal tujuan, ideologi, strategi, taktik, dan partisipan. Gerakan Sosial (lama) cenderung kental dengan dimensi kelas (Marxian) yang terbagi dalam dikotomi kelas borjuis dan proletar; Bergerak pada seputar masalah ekonomi/redistribusi ekonomi yang erat kaitannya dengan masa-masa dimana dinamika perekonomian negara-negara Barat memasuki periode industrial serta kental dengan tujuannya untuk mengubah sistem (menggulingkan kekuasaan) secara radikal/ revolusioner (Mirsel, 2004).

Paradigma Gerakan Sosial baru bertumpu pada dua klaim utama yaitu: Pertama, Gerakan Sosial Baru merupakan 
produk peralihan dari perekonomian industrial menuju post-industrial. Kedua, Gerakan Sosial Baru bersifat unik dan berbeda dengan Gerakan Sosial di era industrial.

Dari segi ideologi, Gerakan Sosial Baru masih banyak dipengaruhi ideologi sosialisme walaupun tidak lagi didominasi dimensi pertentangan kelas seperti Gerakan Sosial (lama). Tujuan yang ingin dicapai Gerakan Sosial Baru tidak lagi untuk menggulingkan kekuasaan formal, akan tetapi lebih pada memperjuangkan “ruang”/makna bagi kelompok-kelompok tertentu, memperjuangkan kualitas kehidupan (quality of life), berbicara mengenai life style, serta bergerak dalam masalah non-redistribusi ekonomi, serta non-kekerasan. Walaupun tidak bersinggungan dengan masalah ekonomi, ruh Gerakan Sosial Baru adalah melawan negara dan hegemoni pasar.

Taktik yang digunakan Gerakan Sosial Baru dalam mewujudkan tujuannya berorientasi pada taktik anti-institusional, anti-birokratik, bergerak di luar jalur politik normal, lebih sebagai gerakan kolektif/aksi bersama tanpa ada kepemimpinan yang ketat dan memobilisasi opini publik untuk meraup pengaruh politik (Nelson, 1997).
Gerakan Sosial Baru dimotori oleh kelompok menengah dan pelajar sebagai partisipannya. Hal ini seolah menegaskan bahwa dalam kerangka Gerakan Sosial Baru, Marxisme sudah tidak dianggap relevan lagi saat ini.

Sebagai salah satu negara berkembang, Indonesia ternyata merupakan lahan subur bagi tumbuhnya gerakan-gerakan yang mencoba melawan pasar serta sistem yang dianggap mainstream baik secara langsung maupun tidak langsung. Atau sebaliknya, ada pula gerakan-gerakan yang hanya sekedar memperjuangkan identitas tanpa ada tendensi politis.

Gerakan sosial yang muncul di Indonesia menjadi menarik karena Indonesia sendiri merupakan negara yang belum memasuki era industrial, alih-alih sebagai negara post-industrial. Oleh karena itu, gerakan sosial yang muncul di Indonesia sebagian besar merupakan gerakan yang terinspirasi dari Barat, atau beberapa merupakan bagian dari jejaring organisasi sosial Internasional yang berpusat di negara Barat.

Dalam konteks gerakan yang dilakukan Komunitas Reresik Sampah Visual, komunitas ini murni gerakan lokal. Cirinya mendekati ciri gerakan sosial baru yaitu terletak pada isu-isu yang diusungnya, 
keanggotaan yang sifatnya longgar dan terbuka, serta non-kekerasan dan nonideologis.

Meskipun berbeda dengan yang ada di Eropa, tetapi apa yang diperjuangkan komunitas di Indonesia dari segi ide dan kontennya tidak jauh berbeda dengan yang di Eropa. Indonesia merupakan negara berkembang yang dalam perkembangannya masih ada banyak permasalahan yang berhubungan dengan sistem dan terutama tarik-menarik kepentingan antara politik dan ekonomi. Permasalahan tata visual iklan media luar griya sendiri, berhadapan dengan tarik-menarik kepentingan antara tuntutan atas hak warga untuk mendapatkan ruang publik yang nyaman, dengan kepentingan pemerintah daerah untuk mendapatkan pemasukan pajak reklame yang tinggi.

\section{F. KESIMPULAN DAN SARAN}

Komunitas Reresik Sampah Visual, meskipun merupakan murni gerakan kemasyarakatan lokal tetapi dapat dibaca sebagai gerakan sosial baru karena memiliki kemiripan antara lain karena memperjuangkan kualitas kehidupan (quality of life) yaitu tata visual iklan media luar griya di ranah publik Yogyakarta, serta bergerak dalam masalah non-redistribusi ekonomi, serta non-kekerasan.
Sebagai gerakan kolektif/aksi bersama tanpa ada kepemimpinan yang ketat dan memobilisasi opini publik untuk meraup pengaruh politik, Komunitas Reresik Sampah Visual memanfaatkan jejaring sosial media, tulisan opini, diskusi forum, dan melakukan aksi razia di jalanan untuk menderaskan opininya.

Dalam masalah tata visual iklan media luar griya, dengan berubahnya landscape komunikasi yang disebabkan oleh perkembangan teknologi maka pengelolaan media iklan tidak sekedar membutuhkan media planning tetapi juga communication design dan screen exposure management. Ini membutuhkan masterplan dari pihak pemerintah agar tata visual iklan media luar griya misalnya, tidak sekedar bicara point billboard yang berpotensi menghasilkan keruwetan dan sampah visual ketika semua berlomba memasang iklan di point tersebut serta untuk mengejar target Pendapatan Asli Daerah (PAD) melalui pajak reklame, tapi juga public eye management.

Berpautnya suatu gerakan sosial dan dinamika perubahan landscape komunikasi inilah yang dapat mendorong terbangunnya budaya baru. Meskipun perubahan budaya bukan suatu hal yang mudah, akan tetapi hal ini dimungkinkan dengan adanya 
penderasan opini dan diskusi yang rasional yang seharusnya makin masif dan sinergis.

\section{DAFTAR PUSTAKA}

[1] Mirsel, Robert. (2004). Teori Pergerakan Sosial, Yogyakarta: INSIST Press.

[2] Moleong, L. (1999). Metodologi Penelitian Kualitatif. Bandung: PT. Rosda Karya.

[3] Pichardo, Nelson A. (1997). "New Social Movements : A Critical Review", Annual Review Of Sociology, 23; ABI/ INFORM Global pg.411.

[4] Sachari, Agus dan Yan Yan Sunarya. (2001). Desain dan Dunia Kesenirupaan Indonesia dalam Wacana Transformasi Budaya. Bandung: Penerbit ITB.

[5] Setiyono, Budi (ed.). (2004). Reka Reklame, Sejarah Periklanan Indonesia 1774-1984. Yogyakarta: Kerjasama Pengurus Pusat Persatuan Perusahaan Periklanan Indonesia dengan Galangpress.

[6] Widyatama, Rendra. (2007). Pengantar Periklanan. Yogyakarta: Pustaka Book Publisher.

[7] Winarno, Bondan. (2008). Rumah Iklan, Upaya Matari Menjadikan Periklanan Indonesia Tuan Rumah di Negeri Sendiri. Jakarta: Penerbit Buku Kompas. 